\title{
EL DIARIO DE WALDECK
}

\author{
P O R \\ J U S T I N O F E R N N D E Z
}

$\mathrm{H}^{\mathrm{ACE}}$ poco tiempo apareció en México un pequeño libro ( $18 \mathrm{1} / 2 \times$ A $12 \mathrm{~cm}$.) manuscrito en francés conteniendo el Diario de Frédcric Waldeck. ${ }^{1}$ Según se sabe, la continuación del Diario y otros papeles de Waldeck se conservan en la Newberry Library de Chicago, en la Colección Edward E. Ayer.

La parte del Diario que vamos a considerar consta de 148 páginas manuscritas, más un colofón. Tres páginas al principio contienen datos sobre los hijos de Waldeck: una mujer, Carolina, y dos hombres: John y el pequeño Fritz, la dirección de María, su esposa, en Londres, 207 Sloan Street, y algunas otras; también una lista de la ropa que guardaba en su equipaje y su valor pormenorizado. Waldeck era tan meticuloso que anota hasta el número y la marca de su reloj.

Nuestro Diario abarca solamente del día 12 de enero de 1825 al 28 de febrero de 1826 , es decir, apenas más de un año. Allí constan los primeros pasos de Waldeck en México y las vicisitudes de su estancia en las minas de Tlalpujahua, a donde vino a trabajar.

Fréderic von Waldeck, Barón de origen alemán, habia nacido en Praga en 1766 y más tarde adoptó la ciudadanía francesa. Estuvo en

1 Pertenece a la Biblioteca de Porrúa Hnos. y Cía. Es por bondad de sus actuales dueños que me es posible dar cuenta aquí por la primera vez de su contenido, por lo cual les expreso mi agradecimiento. 
Africa y a su regreso estudió pintura con Vien -quien fue maestro de David- y Prud'hon. Se había educado, pues, en la escuela clásica. Fue militar en la expedición francesa en Egipto, en 1799, y corsario en los mares de la India. Vino a América en un primer viaje y visitó Chile y Guatemala, cuyas antigüedades dibujó. Regresó a Europa, donde contrajo matrimonio por segunda vez, según parece, y se estableció con su familia en Londres, cerca de los 60 años de edad. Tenía su hija Carolina 17 años y su hijo John 18; su esposa era Maria Iarow, de 35, con quien se casó el 27 de febrero de 1820 , cerca de Durham; de ella había nacido Fritz, de 4 años de edad cuando resolvió Waldeck venir a México. Parece que el objeto de su viaje era dibujar las ruinas de Palenque y las de Chiapas, si bien no lo consigna en su Diario. Encontró empleo en una compañía minera de Inglaterra y fue la forma en que pudo hacer su segundo viaje a América.

Con la nota: "Diario de mi estancia en Tlalpujahua, que terminaría el 14 de febrero de 1826", inserta en la primera página, empieza el Diario, cuando Waldeck se encontraba aún en Londres haciendo los últimos arreglos con el italiano Rivafinoli, encargado de las minas de Tlalpujahua por cuenta de una compañia inglesa.

Rivafinoli le adelantó dinero para comprar cuanto le fuera necesario para el viaje y su estancia en México. Todo el mes de febrero y parte de marzo se ocupó Waldeck en adquirir y empacar un sin fin de cosas que consigna escrupulosamente en su diario, anotando su valor. Además de instrumentos, como un teodolito, y materiales, compró zapatos, pantuflas, cepillos, etc., una silla de montar, dos camas de fierro y mandó arreglar su guitarra. En dos cajas iban sus libros: una Enciclopedia, un Diccionario filosófico, un Tratado de Miniaturas, unos grabados de las Mil y una Noche, un Lexicon griego, una edición de Montesquieu, una Historia Antigua, una Historia Natural, un tratado sobre los músculos, la Odisea, grabados de monumentos franceses, Plutarco, Xenofonte, cien afiches de anuncios de teatro..., de todo to cual anotó el valor.

Por sus compras se ve que parecia tratarse de una expedición bien preparada; por sus libros se comprende que Waldeck era hombre de educación refinada. 


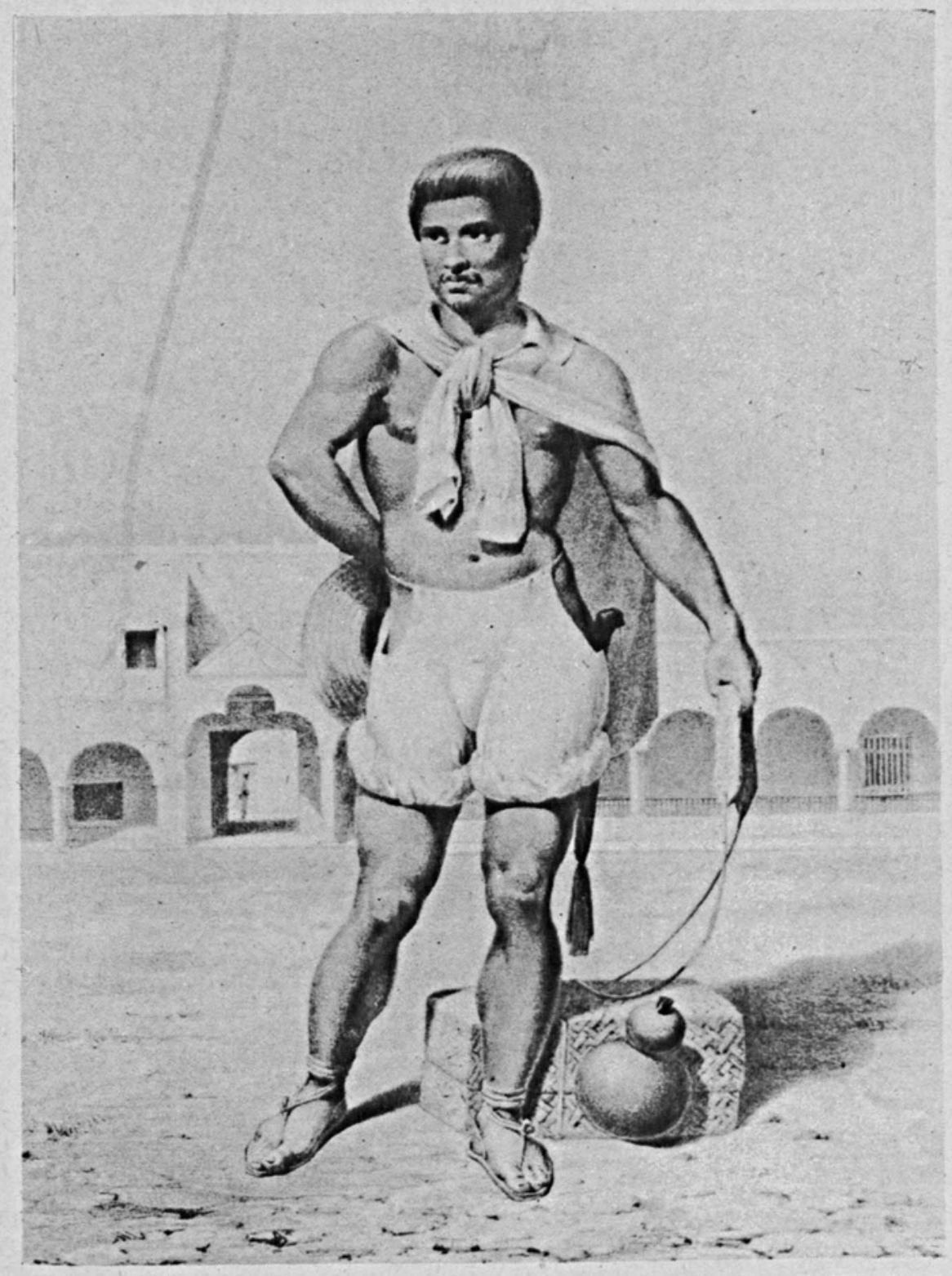

Indio contrabandista del Interior. Dibujo del natural por Waldeck. Litografía de Jules Arnout. (Reproducido del "Voyage Pittoresque e Archéologique dans la Province D'Yucatan”, par Frédéric de Waldeck. Paris, 1838.) 
Ocupado durante el día en sus adquisiciones y en su empaque, Hevaba por las tardes y las noches vida social. Entre sus amigos figura un holandés que vino también a México, Van Lede. Con él va al teatro, al Adelphy, para ver "Table talk", de Henry. En otra ocasión va al Covent Garden, donde representaban "Der Frisshütz".

$\mathrm{Y}$ aun, otra noche va al Drury Lane a ver a Kune Tower en el papel de Otelo. Por las tardes tomaba té en varias casas de amigos. Un día es presentado por Rivafinoli a la Comisión de Minas. E1 27 de febrero recuerda que es el aniversario de su casamiento.

Waldeck tenía devoción por su familia. Cuando llegó el día de la partida, marzo 9 de 1825, se quedó en casa con su esposa y se despidió con precipitación. Escribe: "Sólo Dios sabe la prueba porque paso. No la puedo expresar..." Llega a Portsmouth al dia siguiente y su mania de anotar el precio de las cosas lo lleva hasta asentar el valor de una botella de limonada.

El velero "Sophia" no levantó anclas sino hasta el 14 de marzo. Tuvieron mal y buen tiempo. Waldeck se enfermó "por primera vez", anota. Va con otros compañeros y entre ellos su amigo Van Lede. AI mes de haber salido de Londres recuerda a sus hijos y escribe: "... por ellos me resigno a sufrir. Lo juro." Pasan la Isla de Nevis. Aparece un barco pirata al que sueltan un tiro y cambia de rumbo. Llegan a Jamaica el 28 de abril. Antes habia tenido un disgusto con Mr. Fourni y con Van Lede, a quien jura no volver a ver al llegar a Tlalpujahua. Visita la ciudad de Kingston. $Y$ continúa el viaje. Días de calma en que avanzan poco. Waldeck hace guardia algunas noches. Avista otro barco pirata. Anota lo que le costó el lavado de ropa a bordo. $Y$, por fin, después de tres meses de travesía, ancla el velero frente a Tampico el 9 de mayo.

De la Barra de Tampico va a Pueblo Viejo, por vía fluvial, en canoa, de las construídas por los indios y a las cuales les ponían velas. Era peligroso, dice Waldeck, por los caimanes en el río. En Pueblo Viejo la mejor posada era la de un negro de Nueva Orleans. Ya alli empezaban las molestias del trópico, los mosquitos, la fiebre, que duraba de agosto a octubre. Al sentarse a la mesa le sorprende la variedad y el número de platillos. En una casa grande se alojó con otras siete personas. Al día siguiente visita la población: ve la iglesia, el cuartel, la fuente 
donde se lavan las gentes y le sorprende la belleza de algunas indias jóvenes y su manera de vestir que le recuerda Egipto y Etruria. Dibujó a una de ellas muy bonita, lavándose; otra con un cántaro en la cabeza y un indio "bello como una estatua antigua"; también dibujó la fuente.

Pero las sorpresas agradables van junto con las "niguas", que se meten en las uñas de los pies y las "garrapatas", que se pegan a la piel... Waldeck compra una hamaca, un sombrero de palma y una red para su cama. Va al monte y dibuja un árbol extraordinario.

El domingo las mujeres se visten muy bien, con trajes de seda $y$ satín $\mathrm{y}$ velos con lentejuelas. Las casas están rodeadas de árboles de zapote. Cortan la carne de un modo desagradable, en tiras que ponen a secar al sol, como los bushman africanos.

E1 17 de mayo salió Waideck con el señor Moro de Pueblo Viejo para dirigirse a su destino final, pero habia de llevarles el viaje casi un mes. Van en mulas o en caballos. Duermen en alguna choza en hamacas, o a la intemperie en el monte cuando no es posible otra cosa. Observa Waldeck que hay muchos loros. $\mathrm{Y}$ en la noche "moscas fosforescentes" (luciérnagas). Van por Arroyo del Monte, "Los Organos", Suluoama, Los Ranchos de Loma Alta, la hacienda de "Tantián", rodeada de grandes montañas, Santa Catalina, un pueblo en que dibuja la iglesia, y los "cerros de San Juan". Los indios bailaron allí toda la noche; las mujeres iban peinadas con lazos blancos trenzados en el pelo a manera de coronas y llevaban un chal blanco bordado en rojo con un agujero en el centro por donde meter la cabeza. Los niños completamente desnudos llevaban reliquias en el cuello.

A los cinco dias de jornada Waldeck ya no aguantaba el dolor de las piernas, que tenia hinchadas. Rancho de Ponticla, Tecomata, donde fueron muy mal recibidos y no quisieron venderles nada; tuvieron que dormir en el monte, a merced de la lluvia. Waldeck se consolaba pensando en su familia y rezando a Dios "... este viaje me ha hecho sufrir mucho". Llegaron a la Hacienda de la Pastoria, donde vió unos toros enormes; por primera vez comió tortillas. Luego, Rancho Nuevo. Allí se bañaron en el río y pereció ahogado su guía, un joven indígena. En Chicontepec pagaron al Alcalde el entierro del guía y las misas. Hizo un. dibujo de la iglesia. El pueblo se preparaba para la fiesta de Corpus Christi. Después, Rancho de Chilahuayapa, donde fueron bien recibidos. Anota Waldeck la costumbre indigena de guardar las monedas en las orejas. Al salir de Tierra-Caliente entraron a la Cañada (que debe ser 
la Vega de Metztitlán). Cuacoyoco... la diversidad de plantas, su riqueza y colores y el tamaño de los arbustos, todo parecía obra del pintor, es decir del Creador ... Tlaculuca, Chapula, donde la iglesia estaba pintada de rojo, amarillo y blanco, con su portada tallada burdamente con querubines y palmetas griegas, todo lo cual producía un bizarro efecto. Waldeck siguió por la Cañada y dice que aquello no era América, sino Calabria, todo tenía un aire italiano. Y llegó a Pinolco. Siempre le ađmira el paisaje y la vegetación; en verdad había cruzado la huasteca potosina y la hidalguense, para llegar a Zacualtipán. Adelante empezó a ver magueyes y desde lejos las montañas de Real del Monte. San Bernardo, Río Grande y Atotonilco el grande, que describe y encuentra en su iglesia, entre otros cuadros, un Bronzino, muy maltratado y mutilado. Hizo un dibujo del claustro y del paisaje al fondo, pues estaba instalado en la torre. Pasaron la noche en la mejor casa y habia varias jóvenes bellas que cantaron y bailaron. Un día después partieron hacia Real del Monte y llegaron a Pachuca. Alli elogia la iglesia de San Francisco, sin igual en Europa; su escultura y el dorado son perfectos, ricos y de muy buen gusto, lástima que no hubiera un cuadro; el claustro y la enorme huerta. Toda la cultura de Europa está aquí, dice Waldeck.

De Pachuca siguieron por San Agustín, Tetepango, San Pedro y Tula. De esta última población admira el puente y la iglesia, pero observa que ésta ha sufrido mucho con la guerra de Independencia; hizo un dibujo de la ciudad; vió una iglesia en ruinas, San Lorenzo. Al amanecer partieron, pasando por un valle "muy rico y $\tan$ bien cultivado como podría serlo en Inglaterra", para llegar a Xilotepec. Allí vió el "Juego del Volador". Después del rancho de Pidlua, San Andrés de Milpa, en donde le llamaron la atención las indumentarias de varias clases de hombres $y$ mujeres; había alli dos minas de oro que no habian sido explotadas, $\overline{\mathrm{Pa}}$ saron por un pueblo llamado Tlacomulco y llegaron a la hacienda de La Hordana, en donde esperaba todo el mundo al señor Rivafinoli, de México, quien llegó a medio día. Salieron al día siguiente y, por fin, el 8 de junio de 1825 llegaron a Tlalpujahua.

Salieron a recibirlos el Alcalde, el Comandante y el Cura, acompañados de los principales vecinos y escoltados por ellos entraron a la población con repique de campanas y cohetes lanzados desde las minas y les fue servida una comida espléndida en vajilla de plata. La ciudad tiene cuatro iglesias, escribe Waldeck; la Catedral es de piedra roja con mucha escultura; había también un convento habitado por un solo her- 
mano. Tlalpujahua estaba mitad en ruinas y era difícil encontrar alojamiento. En la cena habia -observa el viajero- chile en las salsas y pulque, que no tenia alli tan mal olor.

La estancia de Waldeck en Tlalpujahua no fue feliz. Sigámoslo a grandes rasgos. Desde los primeros días se sintió enfermo y débil (diarrea y hemorroides; las pulgas). Orelli y Van Lede se fueron a México y él se instaló en los cuartos del primero en el incómodo convento. Había escrito hasta entonces cuatro cartas a su mujer. Llegaron algunas de sus cosas muy maltratadas. Vendió unos cubiertos y Rivafinoli le previno que no debía hacerlo, o le quitaría sus cosas. Van Lede lo había mal impuesto con Rivafinoli. Una carta más a Maria; echa de menos a su familia. Hace dibujos: una vista de Tlalpujahua, unas tortilleras.

No mejoró su situación durante el mes siguiente, julio. Sin noticias de María y enfermo; soñaba con barcos y tenía crisis sentimentales pensando en su pequeño Fritz. Dibujaba: una máquina hidráulica para quebrar, batir y mezclar el mineral... una joven lavándole el pelo una amiga ... Escribió unas reflexiones sobre las costumbres mexicanas. Los muebles que llegaron de México estaban muy mal hechos, y anota "los mexicanos están completamente en la infancia y creo que necesitarán mucho tiempo antes de que puedan hacer cosas pasables". Cuando fué a ver la casa nueva en construcción, exclama “... nunca he visto gentes más perezosas que los indios, no trabajan sino dos horas al dia, si acaso, y el resto del tiempo lo pierden hablando y riendo entre ellos".

No parece que Waldeck fuera simpático a sus jefes y compañeros. Yavole, a sus ojos era un pedante; Rivafinoli le dijo que se pusiera a trabajar, pues Van Lede le había informado que se hacía el enfermo y que pensaba abandonar la Compañía. Van Lede no le había hecho en la vida sino perradas. A pesar de todo fué con Bossi en busca de una mina de oro y encontraron muestras cargadas de ese metal ... y escribe: "Procuraré escarbar más sin ser visto." Con Galli parece que la llevaba mejor, pues hasta le prestaba dinero y el italiano le daba cuenta de sus descubrimientos arqueológicos. Por fin se instaló en la nueva casa y tomó posesión de los talleres de la Compañía.

Rivafinoli era insolente con él y llegó a decir que evitaria que cualquiera de los oficiales se suscribiera a la obra que Waldeck proyectaba (seguramente sobre México y sus costumbres, con ilustraciones). Pero 
tenía algunos pasatiempos: el hermano del cura tocaba bien la guitarra; jugaba y ganaba de vez en cuando y el espectáculo de la gente de la tierra era atractivo. Vió a los indios danzar frente a Santo Santiago, en la iglesia, y uno personificaba el Rey Moro.

Siempre $\sin$ noticias de Londres, Waldeck desesperaba. Siguió teniendo pesadillas: que Van Lede le anunciaba la muerte de su hijo Fritz; que Fritz estaba enfermo; que él se caía al agua desde un barco y dos hombres le ayudaban a subir de nuevo; el agua era clara. Terminaba bendiciendo a su familia.

A fines de agosto no le llegaban ni cartas, ni instrumentos. La fiebre hizo presa de él, se encontraba débil y descorazonado. Si algo me pasa -escribe- ¿no tendré un médico? Pero mejoró un poco.

L.as noticias de México no eran halagadoras. Se decía que una escuadra francesa había desembarcado tropas en Cuba y que parecia que también en Alvarado, lo cual, si era verdad, no podía ser consolador.

Vendió un lote de cuchillos y tijeras; después una caja de navajas de rasurar; cambió su dinero en doblones. Por la noche del 23 no pudo dormir a causa de los cohetes -en la mañana habían tenido lugar las procesiones-; celebraban el día de San (Felipe).

El hermano del Cura le sugirió que podría vivir en México sin mucho trabajo pintando miniaturas, y le encargó un retrato, sin intención de pagárselo. Mas, pensaba "Creo que mi libro se venderá bien en Londres".

Para celebrar el día de San Gaitano, patrón del Señor Moro, se reunieron, pero Galli invitó a dos padres del convento, y escribe Waldeck “. . como yo no quiero a esa raza, me enojó y me dió dolor de cabeza". Sin embargo, un hermano del convento le prestó un folleto titulado Apología de la Aparición de la Virgen de Guadalupe, para extraer de él la historia.

En los cimientos de la nueva casa descubrieron un tesoro. Rivafinoli le dijo que otros oficiales se quejaban de que no trabajaba, pero, dos días antes había escrito en su diario: "Cada momento que pasa sin poderme ocupar de los deberes de mi contrato, me son dolorosos." A fines de mes los útiles no llegaban aún.

Transcribió la historia de la Aparición de la Virgen de Guadalupe y la tradujo en parte (al inglés). Un día festejan el cumpleaños de Galli ; otro cena en casa de Rivafinoli; otros dos emplea en dibujar una vista del nuevo camino, para que vieran en Londres los progresos de ese trabajo. 
Waldeck era un espíritu meticuloso; anotaba siempre sus gastos y sus ganancias; numeraba las cartas escritas a su mujer y no olvidaba de registrar sus sueños. A fines de septiembre su situación mejoró apenas, en algún aspecto, mas empeoró en otros. Seguia dibujando una vista general de Tlalpujahua.

Un día soñó que "visitaba los muslos de una joven que tenía una fuerte erupción", y a la mañana siguiente supo que la hija de la cocinera tenía sarampión. Había epidemia en México y el mal se empezaba a hacer sentir en Tlalpujahua.

"... un nuevo tormento, mis cajas no llegarán antes de dos meses". El correo no le traía cartas, si bien habían llegado para otros y justamente las de él las habian retrasado. Parecía extraño.

Sin papel ni aceite, no podía trabajar. Bossi, escribe Waldeck, está preso de su amor propio; cree saberlo todo "... es muy difícil vivir $y$, a menos de batirse con él, es imposible hacerle entrar en razón".

Por fin, el 16 de septiembre, cuando lo despertaron las campanas y los cohetes, “... que costumbres más estúpidas!", recibió cartas de su familia, que releyó toda la noche.

$\mathrm{Su}$ situación era mala a los ojos de sus jefes y compañeros. $\mathrm{Mr}$. Beaufoy le dijo que como no trabajaba para la Compañia no podía ponerlo en la lista de aumentos de salarios y que sabia que deseaba abandonarla. Waldeck le contestó que trabajaría si tuviera instrumentos y que no pensaba irse antes de demostrar lo que sabía hacer. Presentia que algo malo se tramaba contra él. Rivafinoli le dijo que habían decidido que las máquinas se hicieran a la manera del país y que, por lo tanto, ya no tendría que hacer modelos.

Pensaba que no podían despedirlo por mala conducta y que de otro modo les costaría una indemnización. Rivafinoli, de todos modos, le daba a comprender que no se quedaria mucho tiempo en la Compañia.

Para colmo de males descubrió, por una carta que Allen escribió a María que ésta le era infiel, lo cual le quitaba el sueño. En sueños vió que se encontraba en Londres, sin saber cómo, y que encontraba a María extraña e infiel.

Hizo un cambio con Sant Angelo, le dió su silla inglesa a cambio de una mexicana. Bossi y Galli estaban enfermos; Waldeck también sufría de la garganta. 
Sus cajas llegaron al fin, pero sus libros estaban muy maltratados, el papel manchado de aceite y sus figuras opacas, rotas; pero arregló todo en la casa nueva.

El mes de octubre fue de mayor actividad para Waldeck, quien era trabajador a su manera y estaba lejos de ser perezoso. Dibujó la Barra de Tampico y también una máquina para amalgama de metal en frío; comenzó una vista de Tampico, al óleo; escribió una memoria sobre la utilidad de un teatro nacional en México, trabajó en preparar materiales para los modelos; los domingos pintaba sus cuadros; proyectó una máquina quebradora. Además Rivafinoli le pidió que pintara un transparente para la fiesta de la Independencia.

El día 3 de octubre, a las 10 de la noche, vió un cometa que corría del Sudeste al Este; tenia una larga cola, pero no muy brillante.

Waldeck no dejaba de escribir a María, no obstante que no recibía cartas. Supo que ella habia estado en las oficinas de la Compañía en Londres, para cobrar, pero que no dejó cartas para él.

En casa de Rivafinoli conoció a Mr. O'Gorman, el hermano del Cónsul en México. Waldeck comunicó a Rivafinoli que había ideado una máquina para quebrar rocas de una vara cuadrada en tres o cuatro horas y éste le prometió 20,000 libras esterlinas si lograba tener buen éxito. El dibujo estaba hecho y Rivafinoli se lo sustrajo.

En Veracruz habían muerto del vómito, según se supo, veintidós personas de la Compañia de Real del Monte.

El 25 bendijeron la salida del socavón y hubo fiesta y comida. Galli preguntó a Waldeck si aceptaria un empleo en México para dirigir la litografia que el Gobierno iba a hacer venir y Waldeck le respondió que siempre que fuera por la misma suma que ganaba en la Compañía. No cabe duda de que Galli había sabido comprender las habilidades de Waldeck, pues ya antes le había propuesto conseguirle la dirección del gran teatro de México, en lo que irian a mitad de utilidades.

"Las gentes aqui son tan ladronas que tengo que guardar bien mis cosas", reflexionaba y escribía Waldeck, al mismo tiempo que hacía un cálculo de sus ganancias: le quedaban 125 libras y en tres años podría ahorrar 303 para volver a Londres.

A fin de mes montó una cámara obscura; le pagaron en la Compañia y Galli también, quien además, le llevó un escarabajo muy bonito.

Harness volvió de México y le trajo la noticia de que no podría obtener la dirección del Teatro, porque se la habían dado ya a un extran- 
jero, quien construiría uno nuevo; pero, le dijo, que con su "Fantasia" 2 podria tener buen éxito y dar clases de dibujo. Hakeen queria que le pintara las enfermedades de los ojos y Waldeck pensaba: "si tuviera doscientos luises partiría inmediatamente". Había también otra especulación posible: establecer un Tívoli, como en París o Londres, pues vendían un sitio magnífico para ello.

A principios de noviembre Waldeck escribió a María con los reproches que merecia su conducta; eran amargos, pero "un corazón que sufre como el mío tiene derecho a quejarse".

Trabajó a medias para la Compañía y a medias para si, en sus cuadros y en su "Fantasia", para la cual hizo una muerte volante Hermess estaba entusiasmado y dispuesto a poner su dinero para montar el espectáculo en un teatro en México.

Galli le regaló un perico y Waldeck pensó que le enseñaría a repetit los nombres de sus hijos. El italiano había recibido carta de México diciendo que cuando Waldeck fuera allá lo pondrian al frente de la litografía del Gobierno. Pero Carlini, un viejo capitán de caballería, no tenía buena opinión del asunto y le dijo que el Gobierno pagaba mal y que había un hombre medio loco en el taller que era la razón por la cual Linati quería cederle su puesto.

La falta de cartas de María agudizaban su nostalgia. Una noche soñó que veía a su pequeño Fritz a través de las rejas de un jardín o de un patio y que al reconocer su voz le tendía los brazos. Cerca de Veracruz se habían perdido dos barcos y eso retrasaria las cartas de María.

A Sant Angelo le robaron su caballo, que había comprado el día anterior en 80 pesos.

El 18 recibió una larga carta de María, retrasada, contándole que se iba a tomar baños a Dover, con Fritz. Rivafinoli le reprochó el porte de carta tan pesada y Waldeck reaccionó contra él, pensando que no soportaría más ser maltratado por un parvenu de su especie, sin educación.

Waldeck no se sentía bien de salud, tenía una hernia. Circulaba por el pais un libelo contra los ingleses que, pensaba, les haría daño.

El 22 pasearon todo el día por Tlalpujahua a Nuestro Señor de los Zapateros, con gran pompa y música, que tocaba el aire de "E1 Rey Dagoberto se puso los calzones al revés", lo cual era muy cómico para un europeo. Tal procesión era para hacer cesar la peste, mas, los Padres,

2. Su "Fantasia" era un espectáculo de guiñol. 
dice Waldeck, siempre sacan al Santo cuando ha pasado el peligro, pues perderia su prestigio si lo hicieran salir al comienzo de la epidemia.

Un día vió a una madre llevando sobre la cabeza a su hijo muerto, en una tabla y cubierto de flores. Esa soledad, escribe Waldeck, era más lúgubre que todos los entierros que he visto.

Rivafinoli era absurdo, pues le dijo, frente a Galli, que si había alguna plata robada a la Compañía era la que Waldeck tenía y que si se quedaba los tres años que pensaba, después no tendría que hacer en México y no ganaría lo mismo. Todo eso dejó perplejo a Waldeck, que no entendió si Rivafinoli queria retenerlo o que se largara.

La falta de cartas le hacía pensar o que el gobierno las retenía para leerlas o que alguien se estaba metiendo en sus asuntos.

Compró a un indio una culebra muerta y Bossi le trajó otra pequeña; era una especie nueva y en su pequeñez parecía una boa.

Diciembre. Bossi le habló seriamente de entrar a medias en el negocio del espectáculo; su intención era viajar con Waldeck; podía tener en México un crédito de 1,000 libras. El Capitán Wilde que vió parte de su espectáculo le dijo que tendría buen éxito pero que era muy difícil encontrar en México un sitio apropiado para presentarlo.

Waldeck seguía sintiéndose mal de su hernia. El 8 recordó el natalicio de su hijo Fritz, en 1820, y el 14, el de María, en 1790. El 9 vió un eclipse casi total de sol. El 22 murió su perico. El 11 de diciembre celebraban la Independencia mexicana (?).

Los asuntos en la Compañía iban mal. Galli renunció tras un violento disgtusto con Rivafinoli y se le obligó a abandonar la población. A fin de mes le escribió diciendo que esperaba encontrarle un empleo lucrativo. Otros dos hábiles obreros habían renunciado también.

Rivafinoli previno a Waldeck que cuando acabara sus modelos se fuera a México, puesto que no podían ser construídos por los indios; que a su edad debía hacer una carrera más rápida y que se fuera a explotar su fantasmagoría.

No paró ahí el asunto. En ausencia de Rivafinoli, Mr. Beaufoy le previno también que en Londres informaria a los directores que sus servicios eran inútiles y que podía quedarse aún seis meses para terminar de pagar su deuda a la Compañía. Según sospechaba Waldeck, Beaufoy deseaba hacęrlo enojar para despedirlo por mala conducta, pero Waldeck se proponía más bien informar algún día en Londres sobre sus maquinaciones inhumanas. 
A fin de mes hizo un dibujo de un indio ofreciendo un cigarrillo a una mujer, vistos por detrás. $\mathrm{Y}$ también dibujó un traje indigena para el Album de Akermann.

La primera quincena de enero de 1826 fue prácticamente la última que Waldeck pasó normalmente en Tlalpujahua. Aún dibujó otra vista de la población, desde el sur.

El señor Arévalo, hermano del cura, habia denunciado dos minas nuevas y tenía una lista de quince más y deseaba traspasar sus derechos a una compañia, para lo cual era necesario que él y Waldeck se vieran en México y arreglaran los contratos de acuerdo con la ley. El Cura mismo fue a ver a Waldeck para hablar de la concesión de las minas y le dijo que escribiría a Galli para que les sirviera de intérprete en el arreglo, pero que debía partir cuanto antes, ya que con la llegada del Capitán Wilde empezarían las especulaciones. Por último, convinieron que se unirían con Waldeck en México para arreglar el asunto.

Waldeck pidió permiso a Rivafinoli para ir a México, con el pretexto de comprar un vendaje apropiado para su hernia, y éste se lo concedió, pero le dijo que cuando presentara su dimisión no se le pagaria el viaje de regreso a Londres. Waldeck pensó que se quejaria para que le hicieran justicia.

El 10 recibió cuatro cartas, una de María, otra de Carolina, una de Roberts y otra de Holtzapfle. La de María era del 9 de septiembre y se quejaba de no tener noticias suyas desde que estaba en Tlalpujahua. ¿Retendrian mis cartas - pensaba Waldeck - o las leerán en la oficina de Broad Street? Fritz estaba enfermo y María no se sentía bien.

Escribió a Carolina y a John; y a Roberts para hacerle partícipe de una sólida especulación que habia propuesto a Holtzapfle.

Por fin, empacó su caja de colores y sus vidrios de óptica, arregló sus cuentas y partió para México el 16.

El camino que siguió fue por Tepatitlán, Cerro de Toluca, Ixtlahuaca, Lerma y Las Cruces, no viajando de noche para evitar las bandas de ladrones. Desde lejos México le pareció muy imponente.

Llegó a medio día a la casa de la Compañia en la calle de Capuchinas y vió a Mr. Dick. Salió para encontrar a Galli, quien lo llevó a presentar con el Conde Linati, con quien almorzó. Otra carta de María le informaba que Fritz y ella estaban aún enfermos. 
Mr. Dick es su principal compañero en México, almuerzan y cenan juntos casi a diario, van a espectáculos y le presenta amigos. Es interesante la variedad de diversiones que habia en la Capital. En los 18 días de su estancia Waldeck asistió a los siguientes espectáculos: Ballet en el Teatro de los Gallos, techado de tejamanil, construído con vigas, en forma octagonal y todo pintado de blanco; "El Barbero de Sevilla", en el que la prima donna tenía lo menos 9 pies de circunferencia y cantaba como una ostra; "Otelo"; "Medea", ballet; "Abraham o la Inquisición"; "Espectáculo Gazza Ladra"; "El solitario", y otros que no registra.

Un día ayuda a Hakin a hacer una operación de catarata; otro visita a Mr. Latour, para ver un manuscrito indigena en papel de maguey y una colección de dibujos, entre los cuales reconoció las mismas antigüedades que habia hecho en litografía para Bertou; otro más, compra el vendaje para su hernia y va al Jardín Botánico, que tenía 100 pies cuadrados a lo sumo (en un patio al sureste del Palacio Nacional) y que con excepción de tres grandes árboles de "Manitos", no era nada especial. Le encargaron la pintura de unas flores e hizo el retrato de Dick. En otra ocasión observa que el profesor de Mineralogía no ha logrado sino cuarenta discípulos en treinta y un años y que el de Química no tenía sino uno y lo mismo el de Física, y exclama: "Vaya un progreso de las Artes tan cacareado por Humboldt."

A Linati lo vió con frecuencia, comía y cenaba con él. Lo llevó con el actor Prieto, "el Talma español", quien le prometió ocuparlo para las decoraciones $y$ las máquinas del teatro y quería también hacer negocio con la "Petromagia". También visitó a Sant Angelo, a cuyo hijo habia conocido en Tlalpujahua. $\mathrm{Y}$ cenó con Mr. Dartez y Mr. Brugière.

Una noche soñó que Fritz estaba muerto. " Dios! has que ese sueño sólo sea una quimera."

Otro día fué de caza en las lagunas de la ciudad, en una canoa de una sola pieza de veinte pies de largo; las lagunas estaban llenas de culebras. Con Dick hace un paseo a caballo por la Alameda; pero rehusó ir a un baile.

Fue a ver la iglesia de Santa Teresa, "que es la más bella de México por el orden de la arquitectura jónica del interior, así como por las pinturas al fresco (de Rafael Ximeno) de la cúpula pintada por un español que acaba de morir; su color recuerda mucho al de Le Sueur". 
En verdad la estancia de Waldeck en México estuvo llena de actividad; conoció a varias personas, trabajó algo, se divirtió bastante y se le abrieron posibilidades.

Waldeck salió camino de Tlalpujahua, acompañado del Conde Cornaro, el 4 de febrero. Llegado alli, procuró arreglar sus asuntos con la Compañia, decidido como estaba a abandonarla. Tuvo discusiones con Rivafinoli, mas, al fin llegaron a un acterdo. Le pagarian 100 libras esterlinas a Maria en Londres y asi consideró pagado su regreso. Le recogieron los útiles que pertenecían a la Compañia. Escribió a Dick para que le buscara alojamiento en México; empacó sus libros y demás objetos; arregló sus cuentas con los que le debian. Su fortuna se componía de 114 libras 7 chelines. Rivafinoli le parecía un imbécil.

Mientras partía en definitiva escribió una Memoria de su estancia en Tlalpujahua, para enviarla a Londres; escribió también otra Memoria al Gobierno Mexicano para la empresa general de los manufactureros.

Soñó que llegaba a una ciudad donde encontraba a María y a su pequeño Fritz en buena salud, pero viviendo en una casa que había sido quemada y amenazaba ruina a cada instante, pues temblaba con sus pasos.

A Bossi le regaló el Diccionario Filosófico de Voltaire, en 14 volúmenes; pero reclamó al Capitán Wilde el $2^{\circ}$ tomo de Humboldt que le había prestado.

Tras de alguna dificultad para conseguir monturas, Rivafinoli le proporcionó unas $y$, acompañado de un obrero llamado Jenkis que iba a México a curarse una pierna, salió de "la infernal Tlalpujahua" el 22 de febrero. Dos días y medio después llegó a México.

Dick le había encontrado alojamiento en el número 3 de la calle de Venegas, en la casa de la viuda del pintor Rafael Ximeno, "que el Rey de España, Carlos IV, había enviado aquí, así como a Tolsa, el escultor (que no es mexicano como lo asegura Humboldt, sino español); Ximeno fue discipulo de Rafael Mengs".

Visitó la Academia: "hay un escultor en madera llamado Patiño que tiene mucho talento, es el único que puede citarse. Me ha ofrecido ser Presidente de la Academia si lo deseaba. Pagan 2,000 pesos, que es lo que tenía en Tlalpujahua y no se ocupan sino 3 horas al dia". 
Hizo visitas. Cenó en casa del Conde Linati. Fué con la señora $\mathrm{Xi-}$ meno a conocer al profesor de Botánica, Cervantes, que era un sabio citado por Humboldt. Tenía una espléndida biblioteca y un laboratorio de farmacia bien equipado. Al día siguiente vuelve a ver a Linati. Recibió carta de Maria; ella y Fritz estaban convalecientes.

El diario concluye con lo siguiente: "Espero hacer algo a pesar del estado de ignorancia en que se encuentran las gentes respecto a las artes. Dick me aconseja ocuparme en la miniatura. Creo que piensa que no tengo dinero y querrá comprarme barato mi espectáculo. Se equivoca. $\mathrm{Va}$ a llevarse el resto de las cosas que tengo para venderlas, para mi ganancia... o la de él."

En la última hoja se encuentra el colofón: "Si este diario cae en manos de alguna persona que estime su valor para mi familia, le ruego enviarlo a Londres: Rowney \& Fosters. 51 Rathbone Place."

El resto de sus andanzas en América es conocido. ${ }^{3} \mathrm{Al}$ instalarse en la ciudad de México en 1826 formó una Sociedad para explotar espectáculos "fantasmagóricos" en su casa, calle de don Juan Manuel $\mathrm{N}^{\circ} 6$; alli también pintaba retratos y daba lecciones de dibujo y pintura. En 1827 hizo las litografías para la Colección de las Antigüedades Mexicanas que existe en el Museo Nacional y en el mismo año litografió la Invitación a las Fiestas de Aniversario de la Independencia. Debe haber ejecutado esos trababajos en las prensas de Linati, antes de que quedasen arrumbadas $y$ sin destino en los corredores del Ministerio de Relaciones.

Entre 1834 y 1836 estuvo en Palenque y en Yucatán, bajo la protección del Gobierno de México, mas comenzó a enviar a Europa dibujos y objetos arqueológicos antes de informar al gobierno, por lo cual se le decomisaron sus dibujos y manuscritos y se le retiró la protección. Waldeck protestó en vano. En 1838 salió a luz en París su libro: Voyage Pittoresque et archéologique dans la Province d'Yucatan (Ameriqua Central) pendant les années 1834 et 1836.

Había sido protegido del famoso Lord Kingsborough, autor de la obra monumental Antiquities of Mexico (1831-1848) y a "su memoria de fuego" dedicó su Viaje a Yucatán.

3 Véase mi Arte Moderno y Contemporáneo de México. México, 1952. Instituto de Investigaciones Estéticas. Universidad Nacional Autónoma de México. pp. 37-38. 
Se pensaria que por sus achaques físicos, que consigna en su Diario, Waldeck no podría vivir por largo tiempo, sin embargo no fue así, pues murió en París a la edad de 109 años, en 1875.4

Conviene ahora preguntarnos qué interés tiene para nosotros hoy el Diario de Frederic Waldeck. En primer lugar es evidente por lo que sabemos de él, que no todos sus proyectos e intenciones los confiaba a su Diario; por ejemplo ¿qué especulación le había propuesto a Holtzapfle?, - bien ¿qué se proponía investigando "sin ser visto" en las minas cercanas a Tlalpujahua?

No cabe duda de que Waldeck era un hombre curioso y medio misterioso en sus asuntos; de refinada educación y sensibilidad, de múltiples intereses $\mathrm{y}$ habilidades en el arte, en las ciencias y en las técnicas, era ante todo un aventurero en el mejor sentido del término y, a veces, quizá, aun en el malo. Ciertamente no era un hombre que despreciara el dinero, sin embargo, o era inepto para este género de especulaciones, o no tenía suerte, o bien, lo que es más probable, le tiraban otros intereses: el arte, sobre todo, y la arqueologia. Porque parece que tuvo oportunidades de negocios en México y no obstante su dedicación principal fue el arte. Tenía curiosidad de conocer esto y aquello, más, por otra parte necesitaba la seguridad y era meticuloso en extremo en sus cuentas. Es una personalidad atractiva en algunos aspectos y poco simpática en otros. Se explica uno que no hiciera buenas migas con un tipo como Rivafinoli y que, en cambio, sí tuviera amistad con Galli y con Linati, hombres de cultura refinada, de que carecían los capataces mineros; mas, no parece que le haya tentado la política, como a los dos italianos. En general era de temperamento equilibrado y tenía dominio de si.

El Diario contiene una serie de observaciones sobre México, además de ofrecer informes que nos dan idea del tipo de persona que era Waldeck. Sobre viajes: por mar, los piratas; por tierra, la ruta de Tampico a Tlalpujahua, los incidentes y observaciones, el modo de viajar; la ruta de Tlalpujahua a México. Hay que recordar que escribió unas Reflexiones sobre las costumbres mexicanas; a Waldeck le pareció que

$4 \mathrm{He}$ tomado algunos datos de su vida del prólogo de D. Manuel Mestre Ghigliazza a la segunda edición del Viaje a Yucatán, traducido por el prologista. Mérida 1903. Edición limitada a 110 ejemplares. 
en materia de técnicas los mexicanos estaban en la infancia y que pasaria mucho tiempo para que progresaran; quizá por eso escribió la Memoria al Gobierno de México para la empresa general de los manufactureros; que los indios eran perezosos; que en Tlalpujahua y en los caminos había ladrones. Le interesaron las costumbres y las indumentarias típicas, los danzantes, las fiestas y celebraciones, si bien los cohetes y el rèdoble de campanas le parecian costumbres estúpidas. ¿Por qué celebrarian entonces la Independencia el 11 de diciembre?

Waldeck tenía conocimientos sobre óptica, botánica y otras ciencias naturales y exactas, pero el teatro era su pasión. Recordaremos que escribió una Memoria sobre la utilidad de un Teatro Nacional en México, que asistió en la Capital a cuanto espectáculo pudo y que su entretenimiento y creación especial era su "Fantasmagoria", o sea el teatro de títeres, que acabó explotando en México hasta donde pudo. No sabemos a dónde han ido a parar sus dibujos y pinturas, salvo aquellos que publicó en litografia. Sus invenciones de máquinas parecen cosas de Leonardo. El libro que proyectaba y que pensaba vender bien en Londres no llegó a publicarse; seguramente era sobre trajes y costumbres típicos; mas en este punto se le adelantó Linati con su libro publicado en Bruselas en 1828.

Pensó dirigir el Teatro de México, pero no fue posible; se le ofreció la dirección de la litografía del gobierno, pero no llegó a hacerse efectivo; se le ofreció la presidencia de la Academia, pero todo quedó en el aire; se le ofreció un gran negocio de minas, pero no tuvo resultado. Sin embargo, fué el segundo extranjero, después de Linati que hiciera litografias en México; el primero en dibujar y litografiar algunos temas de arqueología americana y de los primeros en explorar, desde este punto de vista y el de las costumbres, Yucatán.

Como buen clasicista, le gustó la iglesia de Santa Teresa de México y las pinturas murales de Ximeno. Pero le tocó ver la decadencia de la Academia, por eso no menciona sino a Patiño y en lo general concluye que las gentes se encontraban en estado de ignorancia respecto a las artes.

Un capitulo interesante del Diario de Waldeck es el de sus sueños Hemos visto que los anotaba cuidadosamente. La mayor parte de ellos se refieren a su preocupación por su familia, en especial por su pequeño Fritz y por Maria, su mujer; otros más bien parecen eróticos: el de la 
muchacha y el de la caída al agua, Freud sacaría algunas conclusiones de todos ellos.

El Diario de Waldeck, además de su interés humano, nos ofrece las observaciones, opiniones y anhelos de un hombre de quien parte de su vida está relacionada con nuestra historia del arte y de la arqueología; por eso es un documento más para la historia de los artistas extranjeros en México. 